\title{
Kinetics Study and Simulation of DME Steam Reforming Reaction
}

\author{
Jun Wang, Cong Li \\ College of Automotive Engineering, Shanghai University of Engineering Science, Shanghai, China \\ Email: wangjun_501@163.com
}

How to cite this paper: Wang, J. and Li, C. (2017) Kinetics Study and Simulation of DME Steam Reforming Reaction. Open Access Library Journal, 4: e4022. https://doi.org/10.4236/oalib.1104022

Received: October 12, 2017

Accepted: November 14, 2017

Published: November 17, 2017

Copyright $\odot 2017$ by authors and Open Access Library Inc.

This work is licensed under the Creative Commons Attribution International License (CC BY 4.0).

http://creativecommons.org/licenses/by/4.0/

\begin{abstract}
A CFD (computational fluid dynamics) model has been presented to simulate the steam reforming reaction of DME in this study. A three-dimensional numerical model introduced by the commercial software COMSOL was used to investigate the fluid flow of reformer bed and heating tubes, the energy transport of reformer bed and heating tubes, and the mass transport of reformer bed. The governing equations in the model consist of conservations of mass, momentum, energy and chemical species. In order to optimize the process of reaction, the steam to DME ratio, the inlet temperature, and porosity were investigated. The simulation results showed the changes of temperature distribution, DME conversion and hydrogen production of the steam reforming reaction with different operation conditions.
\end{abstract}

\section{Subject Areas \\ Computational Chemistry}

\section{Keywords}

Dimethyl Ether, Numerical Simulation, Hydrogen, Steam Reforming

\section{Introduction}

Energy is the indispensable material basis of human existence, and is also the driving force of social economy development. The rapid development of economy has brought double crisis of energy shortage and environmental pollution, so hydrogen as fuel for fuel cell vehicles gets rapid development [1] [2]. Dimethyl ether has a high content of hydrogen, non-toxic and the advantages of similar to liquefied petroleum gas (LPG). It is environmentally friendly and easy to store and transport, thus becoming an ideal liquid raw materials used in the reforming hydrogen production [3]. Dimethyl ether steam reforming hydrogen 
production not only extends the application fields of dimethyl ether in the fuel, but also benefits environmental protection, so this technology has the double meaning of energy development and environmental protection. Hydrogen production from steam reforming of DEM is a continuous reaction: The first step is DME hydrolysis into methanol on an acidic catalyst; the second step is to produce hydrogen in the methanol reforming of the metal catalyst. The DME hydration of methanol is a thermodynamic equilibrium limit, but immediately produced methanol steam reforming reaction.

Several reported studies of experimental and theoretical on steam reforming have been proposed. Chang-Feng Yan et al. investigated a micro-reactor with catalyst coated on nickel foam support and the effect of $\mathrm{Cr}$ promoter on performance of steam reforming of dimethyl ether in a metal foam micro-reactor [4] [5]. Francis A. Elewuwa et al. presents a computational parametric analysis of DME steam reforming in a large scale Circulating Fluidized Bed (CFB) reactor [6] [7]. A kinetic rate of total combustion of DME based on copper-based catalyst has been presented by Feng et al. [8]. Hydrogen production from steam reforming of DME has been modeled and simulated by Li C et al. [9].

\section{Numerical Model}

\subsection{Physical Model}

The simulated microreactor consists of three domains: catalyst bed, heating tubes, and insulating jacket.

\subsection{Model Assumptions}

Assuming that the flow regime is stable, laminar and incompressible, the gas mixture is considered as ideal gas. The mixture consists of six species: DME, $\mathrm{CH}_{3} \mathrm{OH}, \mathrm{CO}_{2}, \mathrm{CO}, \mathrm{H}_{2} \mathrm{O}$, and $\mathrm{H}_{2}$. In addition, the volumetric flow is in the axial direction, while the mass transfer occurs mainly in the lateral direction of diffusion to the reactor wall. Therefore, the three-dimension model is adequate to cope with the reforming reaction.

\subsection{Governing Equations}

Based on the above assumptions, the mass, momentum, energy, and species equations of the porous region can be written as follows.

\subsubsection{The Energy Transport Equations}

The average temperature distribution equation of the porous bed:

$$
\left(\rho C_{p}\right)_{t} \frac{\partial T_{s r}}{\partial t}+\nabla \cdot\left(-k_{s r} \nabla T_{s r}\right)+\left(\rho C_{p}\right)_{f} \cdot u \cdot \nabla T_{s r}=Q
$$

In the above equation, $\rho$ denotes the gas density, $T_{s r}$ is the temperature and $k_{s r}$ is the thermal dispersion of the reformer bed. $Q$ represents a heat source, and $u$ is the fluid velocity.

The energy transport equation in heating tubes: 


$$
\nabla \cdot\left(-k_{h t} \nabla T\right)+\rho C_{p} \cdot u \cdot \nabla T=0
$$

where $k_{h t}$ is the thermal conductivity of the heating gas.

\subsubsection{The Mass-Balance Equation of Reformer Bed}

$$
\nabla\left(\rho \omega_{i} u-\rho \omega_{i} \sum_{j=1}^{n} D_{i j}\left(\nabla x_{j}+\left(x_{j}-\omega_{j}\right) \frac{\nabla p}{p}\right)-D_{i}^{T} \frac{\nabla T}{T}\right)=R_{i}
$$

Here, $\omega_{i}$ is the mass fraction of species $i, x_{j}$ is the molar fraction of species $j, D_{i j}$ is the $i j$ component of the multicomponent Fick diffusivity. $D_{i}$ denotes the generalized thermal diffusion coefficient, $T$ is the temperature, and $R_{i}$ is the reaction rate.

\subsection{Boundary Conditions}

The inlet and outlet boundary conditions describe a pressure drop across the bed. All other boundaries are impervious, corresponding to the condition:

$$
-\frac{\kappa}{\eta} \nabla p_{s r} \cdot n=0
$$

Convective heat transport at the outlet is assumed to be dominant:

$$
n \cdot\left(k_{s r} \nabla T_{s r}\right)=0
$$

For the flow of heating gas in the tubes, the boundary conditions are:

$$
\begin{gathered}
u \cdot n=v_{0} \\
u=0 \\
p=p_{\text {ref }}
\end{gathered}
$$

\subsection{Chemical Kinetics}

Catalytic steam reforming of DME involves many reactions with different rates, the parameters in Equation (9) for DME hydrolysis into methanol were reported by Feng et al. [8].

$$
r_{\mathrm{DME}}=r_{\mathrm{DMO}^{+}}=k_{F, \mathrm{DMO}^{+}}^{\prime} C_{R_{1}^{+}}-k_{C, \mathrm{DMO}^{+}}^{\prime} C_{\mathrm{DMO}^{+}}
$$

The kinetic equations [10] for methanol steam reforming and decomposition reaction are:

$$
\begin{gathered}
r_{R}=(1-\varepsilon) \rho_{s} k_{R} C_{\mathrm{CH}_{3} \mathrm{OH}} \\
r_{3}=(1-\varepsilon) \rho_{s} k_{D}
\end{gathered}
$$

Here, $\rho_{s}$ is catalyst density, $k_{R}$ denotes the reforming rate constant, $\mathrm{C}_{\mathrm{CH}_{3} \mathrm{OH}}$ is the molar concentration of methanol, $k_{D}$ is the decomposition rate constant.

The kinetic model of WGS reactions is as following [11]:

$$
r_{\mathrm{WGS}}=C_{\mathrm{WGS}} k_{\mathrm{WGS}}\left(p_{\mathrm{CO}} p_{\mathrm{H}_{2} \mathrm{O}}-p_{\mathrm{CO}} p_{\mathrm{H}_{2}} / K_{e q}\right)
$$

where, $k_{\mathrm{WGS}}$ and $K_{e q}$ are the rate constant and the equilibrium constant re- 
spectively.

\section{Validation}

\subsection{Experimental Study}

A reliable model is crucial to simulate the physical phenomena. In order to verify the reliability and accuracy of the simulated model, numerical results and the experimental data under the same conditions were compared. In the experimental system, the steam and DME flow was controlled by the syringe pump, the mixed gas flowed into the reactor filled with a $\mathrm{CuO} / \mathrm{ZnO} / \mathrm{Al}_{2} \mathrm{O}_{3}+\mathrm{ZSM} 5$ catalyst through a mass flow controller. Reactant and product concentrations were measured by gas chromatography.

\subsection{Validation of the Model}

The reactant gas was preheated to $200^{\circ} \mathrm{C}$, and the steam to DME ratio was 5 , the DME conversion and the hydrogen yield are defined as follows:

$$
\begin{gathered}
\text { DME conversion }(\%)=\left(F_{\mathrm{DME}, \text { in }}-F_{\mathrm{DME}, \text { out }}\right) / F_{\mathrm{DME}, \text { in }} \times 100 \% \\
\text { Hydrogen yield }(\%)=F_{\mathrm{H}_{2} \text {,out }} / F_{\mathrm{DME} \text {,in }} \times 1 / 6 \times 100 \%
\end{gathered}
$$

where $F_{\mathrm{DME}}$ is the mass flow of DME, $F_{\mathrm{H}_{2}}$ is the mass flow of $\mathrm{H}_{2}$.

Figure 1(a) and Figure 1(b) shows the comparison of DME and $\mathrm{H}_{2}$ yield respectively between the simulation results and experiment data. The higher hydrogen production and DME conversion of simulation results were probably due to hydrogen spillover or hydrogen leak of the experiment.

The simulation results for DME conversion and yield agree well with the experimental data. Therefore, the numerical simulation error is small and the result is reasonable, the current model can be used to study the reactor.

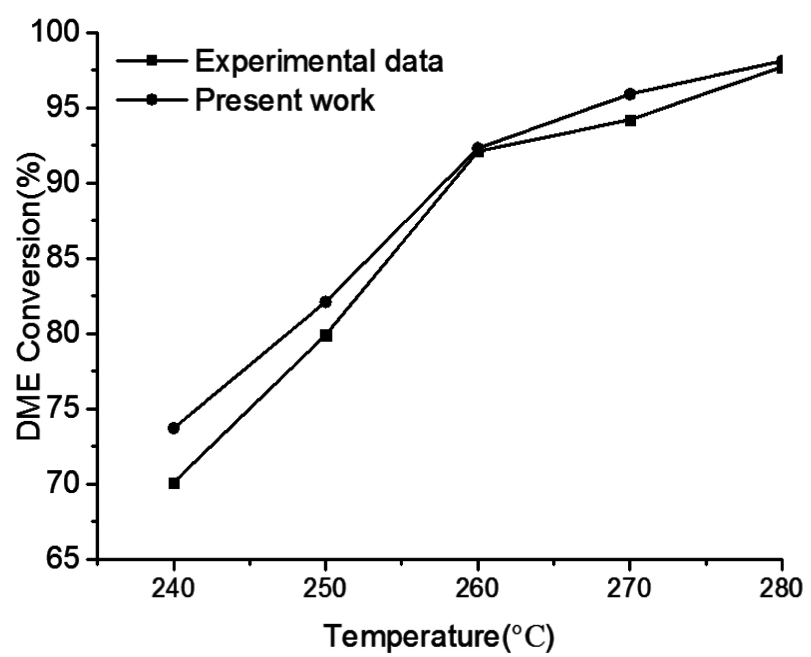

(a)

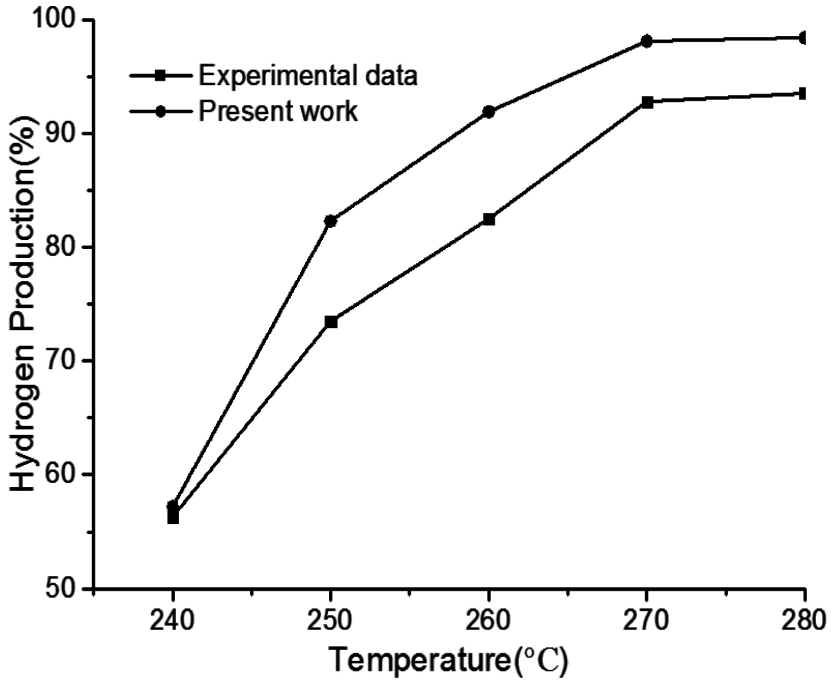

(b)

Figure 1. Comparison between the simulation results and the experimental data. (a) DME conversion; (b) hydrogen production. 


\section{Results and Discussions}

\subsection{Effect of Steam/DME Molar Ratio}

Figure 2(a) and Figure 2(b) shows the DME conversion and hydrogen production as a function of temperature with different ratio of steam to DME. The inlet temperature of mixture gas was $260^{\circ} \mathrm{C}$. The ratio of steam to DME ranges from 3 to 7 .

Figure 2 shows that the DME conversion and hydrogen yield increased with the increase of the steam/DME ratio. The higher steam/DME ratio accelerated the DME hydrolysis reaction and methanol reforming reaction, and the water gas shift reaction was promoted, so as to produce more $\mathrm{H}_{2}$.

\subsection{Effect of Inlet Temperature}

Effect of inlet temperature was shown in Figure 3. Figure 3(a) and Figure 3(b)

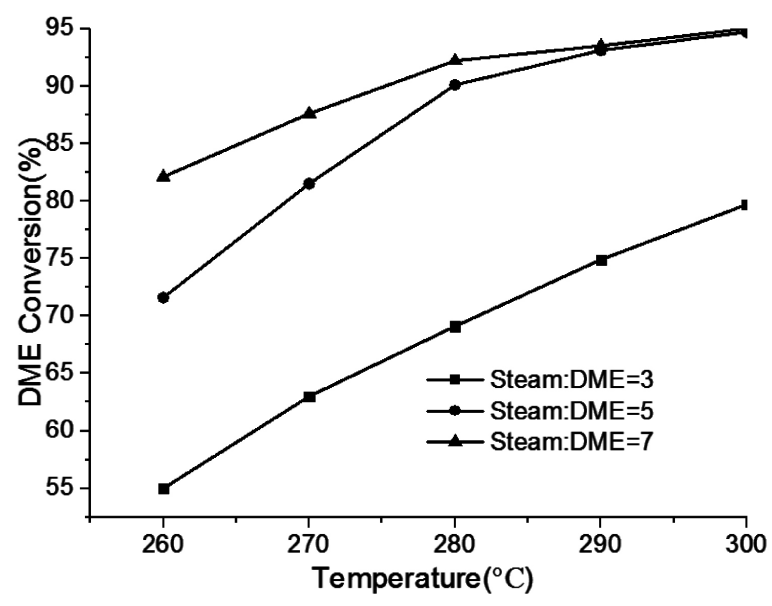

(a)

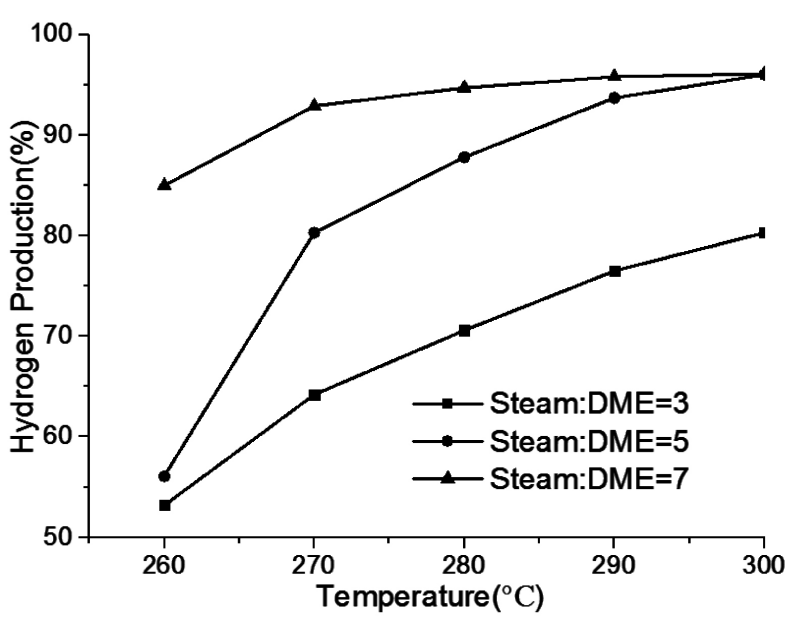

(b)

Figure 2. DME conversion and Hydrogen production as a function of temperature. (a) DME conversion; (b) hydrogen production.

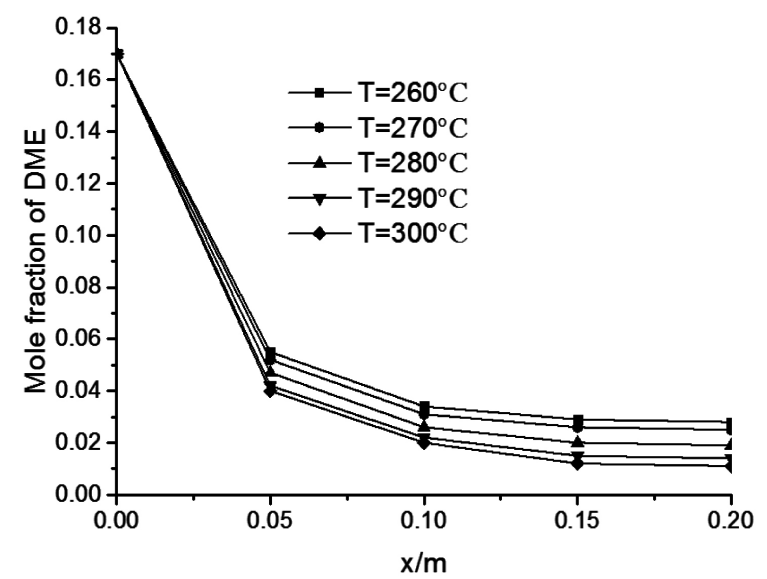

(a)

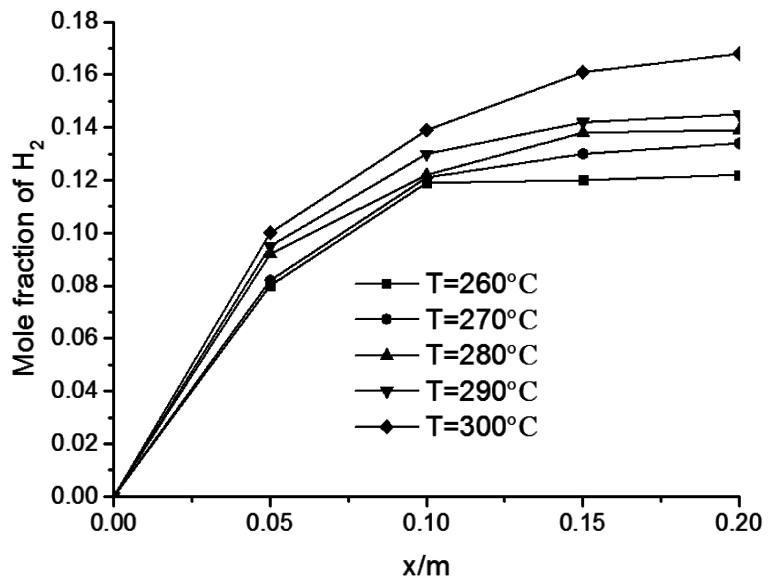

(b)

Figure 3. Effects of temperature on the DME and $\mathrm{H}_{2}$ mole fraction. (a) Mole fraction of DME; (b) mole fraction of $\mathrm{H}_{2}$. 
shows the mole fraction of DME and $\mathrm{H}_{2}$ respectively with the change of gas inlet temperature. As seen in Figure 3, the mole fraction of DME was lowest at the temperature of $300^{\circ} \mathrm{C}$, while the mole fraction of $\mathrm{H}_{2}$ was highest. These results indicated that higher temperature can further the DME hydrolysis, but strengthened the reverse water-gas-shift reaction. A higher temperature promoted higher conversion of DME and higher hydrogen yield.

\subsection{Effect of Porosity}

As shown in Figure 4 was the effect of porosity on the mole fraction of DME and $\mathrm{H}_{2}$. The range of porosity changed from 0.2 to 0.8 .

Figure 4 shows that the larger the porosity, the higher mole fraction of $\mathrm{H}_{2}$, and the lower mole fraction of DME, because the increasing porosity decreased the inlet pressure.

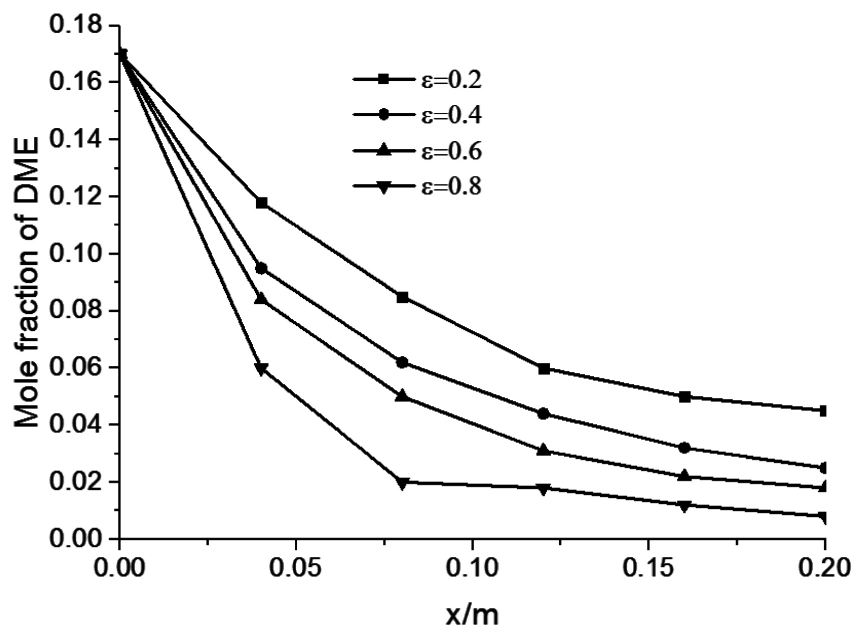

(a)

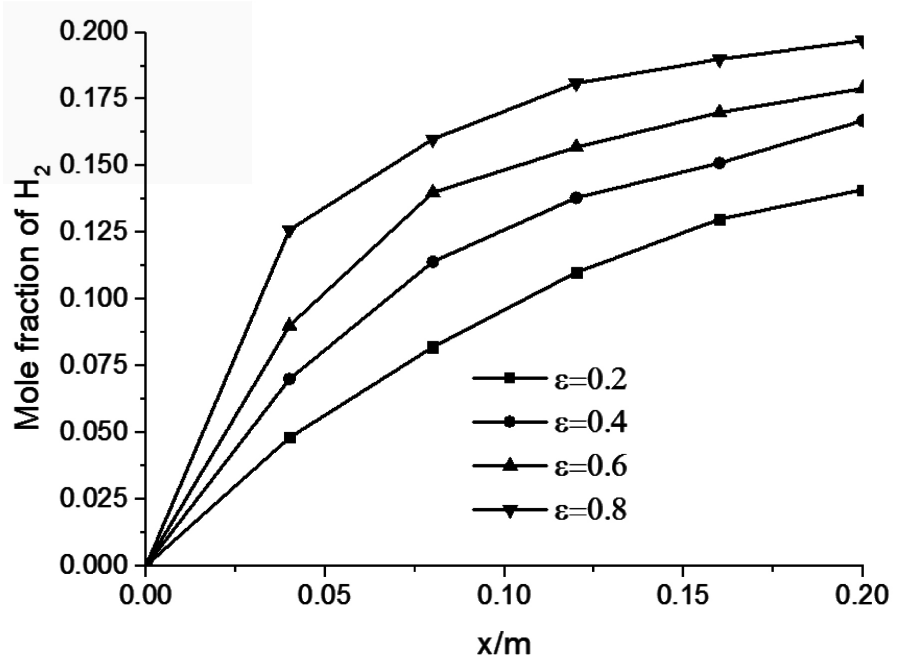

(b)

Figure 4. Effects of porosity on the DME and $\mathrm{H} 2$ mole fraction. (a) Mole fraction of DME; (b) mole fraction of $\mathrm{H} 2$. 


\section{Conclusions}

In this study, catalytic steam reforming of DME was simulated using a three-dimensional CFD model introduced in software COMSOL. On the basis of the model, the process of steam reforming reaction was investigated properly.

The simulated model can reveal the hydrogen production and DME conversion properly, and the conclusions are as follows.

1) The reaction with higher steam to DME ratio can produce more hydrogen and improve the DME conversion.

2) Higher inlet temperature can provide more heat needed for the reaction, so as to accelerate the reaction, and lead to more hydrogen.

3) Larger porosity can bring a higher DME conversion and more hydrogen because of a larger reaction surface and more catalyst. The pressure drop between the inlet and outlet of the reactor was smaller.

\section{References}

[1] Chaubey, R., Sahu, S., James, O.O. and Maity, S. (2013) A Review on Development of Industrial Processes and Emerging Techniques for Production of Hydrogen from Renewable and Sustainable Sources. Renewable \& Sustainable Energy Reviews, 23, 443-462. https://doi.org/10.1016/j.rser.2013.02.019

[2] Alves, H.J., Bley Junior, C., Niklevicz, R.R., Frigo, E.P. and Frigo, M.S. (2013) Overview of Hydrogen Production Technologies from Biogas and the Applications in Fuel Cells. International Journal of Hydrogen Energy, 38, 5215-5225.

https://doi.org/10.1016/j.ijhydene.2013.02.057

[3] Park, S.J., Lee, D.W., Yu, C.Y., Lee, K.Y. and Lee, K.H. (2008) Hydrogen Production from a DME Reforming-Membrane Reactor Using Stainless Steel-Supported Knudsen Membranes with High Permeability. Journal of Membrane Science, 318, 123-128. https://doi.org/10.1016/j.memsci.2008.02.036

[4] Yan, C.F., Ye, W., Guo, C.Q., Huang, S.L., Li, W.B. and Luo, W.M. (2014) Numerical Simulation and Experimental Study of Hydrogen Production from Dimethyl Ether Steam Reforming in a Micro-Reactor. International Journal of Hydrogen Energy, 39, 18642-18649. https://doi.org/10.1016/j.ijhydene.2014.02.133

[5] Yan, C.F., Hai, H., Hu, R.R., Guo, C.Q., Huang, S.L., Li, W.B. and Wen, Y. (2014) Effect of Cr Promoter on Performance of Steam Reforming of Dimethyl Ether in a Metal Foam Micro-Reactor. International Journal of Hydrogen Energy, 39, 18625-18631. https://doi.org/10.1016/j.ijhydene.2014.02.152

[6] Elewuwa, F.A. and Makkawi, Y.T. (2015) Hydrogen Production by Steam Reforming of DME in a Large Scale CFB Reactor. Part I: Computational Model and Predictions. International Journal of Hydrogen Energy, 40, 15865-15876.

https://doi.org/10.1016/j.ijhydene.2015.10.050

[7] Makkawi, Y.T. and Elewuwa, F.A. (2016) A Computational Model of Hydrogen Production by Steam Reforming of Dimethyl Ether in a Large Scale CFB Reactor. Part II: Parametric analysis. International Journal of Hydrogen Energy, 41, 19819-19828. https://doi.org/10.1016/j.ijhydene.2016.08.072

[8] Feng, D.M., Wang, Y., Wang, D. and Wang, J. (2009) Steam Reforming of Dimethyl Ether over CuO-ZnO-Al2O3-ZrO2+ZSM-5: A Kinetic Study. Chemical Engineering Journal, 146, 477-485. https://doi.org/10.1016/j.cej.2008.11.005 
[9] Li, C., Gao, Y. and Wu, C.S. (2015) Modeling and Simulation of Hydrogen Production from Dimethyl Ether Steam Reforming Using Exhaust Gas. International Journal of Energy Research, 39, 1272-1279. https://doi.org/10.1002/er.3330

[10] Suh, J.S., Lee, M.T., Greif, R. and Grigoropoulos, C.P. (2007) A Study of Steam Methanol Reforming in a Microreactor. Journal of Power Sources, 173, 458-466. https://doi.org/10.1016/j.jpowsour.2007.04.038

[11] Chein, R., Chen, Y.C. and Chung, J.N. (2013) Numerical Study of Methanol-Steam Reforming And Methanol-Air Catalytic Combustion in Annulus Reactors for Hydrogen Production. Applied Energy, 102, 1022-1034.

https://doi.org/10.1016/j.apenergy.2012.06.010

Submit or recommend next manuscript to OALib Journal and we will provide best service for you:

- Publication frequency: Monthly

- 9 subject areas of science, technology and medicine

- Fair and rigorous peer-review system

- Fast publication process

- Article promotion in various social networking sites (LinkedIn, Facebook, Twitter, etc.)

- Maximum dissemination of your research work

Submit Your Paper Online: Click Here to Submit

Or Contact service@oalib.com 